\title{
COVID-19 TEDAVISINDE VITAMIN C VE VITAMIN D
}

\author{
VITAMIN C AND VITAMIN D IN COVID-19 THERAPY
}

\author{
Onur ÜNAL ${ }^{1}$ \\ ${ }^{1}$ Süleyman Demirel Üniversitesi Tıp Fakültesi Enfeksiyon Hastalıkları ve Klinik Mikrobiyoloji Ana Bilim Dalı
}

Cite this article as: Ünal O. Vitamin C And Vitamin D In Covid-19 Therapy. Med J SDU 2021; (ozelsayi-1):97-100.

\section{Öz}

Koronavirüs hastalığı 2019 (COVID-19), SARSCoV-2 virüsünün neden olduğu asemptomatik seyirden, solunum yetmezliğinin eşlik ettiği ve ölümle sonuçlanabilen geniş spektrumda klinik tabloya yol açan bir hastalıktır. Korunma ve tedavisinde etkinliği kanıtlanmış seçenek sayısı sınırlıdır. Viral enfeksiyonlar sırasında vitamin ve mineral eksiklikleri olumsuz klinik sonuçlarla ilişkilendirilmektedir. Vitamin takviyesinin akut solunum yolu enfeksiyonu insidansını ve şiddetini azaltabileceğini belirten klinik çalışmalar mevcuttur. COVID-19 pandemisiyle birlikte vitaminlerin hastalıktan korunma ve tedavideki yararlarıyla ilgili araştırmalar artmış olup etkin olduğunu bildiren yayınlar olduğu kadar, bu sonucu desteklemeyen çalışmaların olduğu da gözlenmektedir. D vitamininin virüslere karşı fiziksel bariyerin güçlendirilmesinde, antimikrobiyal peptitlerin üretiminin uyarılmasında ve inflamatuvar sitokin üretiminin azalmasını sağlayarak sitokin fırtınalarının önlenmesinde önemli rolü olduğu belirtilmektedir. Vitamin C uygulamasının COVID-19 hastalarında immün yanııın güçlendirilmesine katkıda bulunarak sağ kalım oranlarını arttırabileceği ifade edilmektedir. Bu derlemenin amacı COVID-19 hastalığında C ve D vitaminlerinin etkisininin değerlendirilmesidir.

Anahtar Kelimeler: Vitamin C, Vitamin D, COVID-19

\section{Abstract}

Coronavirus disease 2019 (COVID-19) is a disease that can lead to a broad spectrum clinical picture, from asymptomatic course caused by SARS-CoV-2 virus, accompanied by respiratory failure and may result in death. The number of proven therapeutic options for the prevention and treatment of COVID-19 is limited. Vitamin and mineral deficiencies during viral infections are associated with adverse clinical outcomes. Clinical studies are indicating that vitamin supplementation can reduce the incidence and severity of acute respiratory infections. With the COVID-19 pandemic, researches on the benefits of vitamins in disease prevention and treatment have increased. Although some studies report that vitamins are effective, it is observed that there are studies that do not support this statement. Vitamin D plays an important role in enhancing the physical barrier against viruses, stimulating the production of antimicrobial peptides, and preventing cytokine storms by reducing inflammatory cytokine production. It is stated that vitamin C application can increase survival rates by contributing to enhancing the imune response in COVID-19 patients. The purpose of this review is to evaluate the effect of vitamin C and vitamin D in COVID-19.

Keywords: Vitamin C, Vitamin D, COVID-19

\section{Giriş}

Koronavirüs hastalığı 2019 (COVID-19), RNA virüslerinden SARS-CoV-2 'nin neden olduğu tüm dün- yayı etkileyen önemli bir halk sağlığı sorunudur (1). Asemptomatik seyirden, solunum yetmezliğinin eşlik ettiği ve ölümle sonuçlanabilen geniş spektrumda klinik tabloya yol açmaktadır (2). Eşlik eden hastalıklar, ırk, sağlık hizmetlerine erişim, genetik faktörler ve ko- 
nağın immün sisteminin durumu klinik seyri etkilemektedir. Tedavisinde SARS-CoV, MERS-CoV gibi çeşitli viral enfeksiyonlardaki deneyimler gözönüne alınarak yararlı olabileceği düşünülen ilaçlar kullanılmakta ve etkinlikleri araştırılmaktadır. Henüz SARS-CoV-2 virüsüne karşı etkinliği yüksek kanıt düzeyleriyle gösterilmiş antiviral bir ilaç bulunmadığından, bağışıklık sistemini ve antioksidan savunma mekanizmalarını güçlendirmeye yönelik stratejilerin, COVID-19'dan kaynaklanan komplikasyonları hafifletmek için etkili olabileceği ileri sürülmektedir (3). İmmün sistem sürekli aktif olmakla birlikte patojenle karşılaşma durumunda savunmada gerekli olan bağışıklık hücrelerinin sayı ve fonksiyonundaki artışın desteklenebilmesi için intiyaç olan vitamin ve mineral gibi substratlar hazır bulunmalıdır. Çok sayıda araştırmada, COVID-19 da dahil çeşitli viral hastalıklarda vitaminlerin konak bağışıklık sisteminin sağlıklı bir şekilde işlemesinde önemli etkisi olabileceği belirtilmektedir. COVID-19'un destekleyici tedavisinin bir parçası olarak vitaminlere olan ilgi artmaktadır.

\section{Vitamin D}

Vitamin D ilk olarak İngiltere'de rașitizm insidansındaki yüksekliğin araştırılması için yapılan çalışmalar sırasında keşfedilen sekosteroid yapıda yağda çözünen bir hormondur (4). Diyetle ergokalsiferol ve kolekalsiferol şeklinde alınabileceği gibi deride güneş ışınlarının etkisiyle 7-dehidrokolesterolden de sentezlenebilmektedir (5). Kolekalsiferol, öncelikle karaciğerde 25. karbon atomundan hidroksillenerek $25(\mathrm{OH})$ D3'e dönüştürülür, $D$ vitamini bağlayan proteinle dolaşıma geçerek böbreğe taşınır. Böbrekte $D$ vitamininin aktif formu olan $1,25(\mathrm{OH}) 2 \mathrm{D} 3$ 'e çevrilmektedir. 1,25(OH)2D3 hücre içerisindeki işlevini reseptörüne bağlanarak göstermektedir (1). Vitamin D reseptörleri bağışıklık hücreleri, deri, iskelet kası dahil çeşitli hücre ve doku türlerinde yaygın olarak bulunmaktadır (6).

D vitamininin immün sistem de dahil olmak üzere bir çok vücut sisteminde rolü olduğu tespit edilmiştir (1). Hem doğal, hem de edinsel bağışıklık sistemini düzenleyen immünomodülatör bir ajan olarak kabul edilmektedir (6). Zarflı ve zarfsız virüslere karşı doğrudan antimikrobiyal etki gösteren defensin, katelisidin gibi peptidlerin ekspresyonunu arttırarak doğal hücresel immün yanıtı arttırır. Defensinler solunum yolu epitel hücreleri arasındaki bağlantı noktaları olan "gap junction", "tight junction" ve "adheren junction"ların bütünlüğünü koruyarak virüslerin invazyonunun önlenmesinde etkilidir $(1,7)$. Vitamin $D$ ayrıca, $T$ helper 1 (Th1) hücre fonksiyonunu baskılayarak, interlökin 6 (IL-6), interferon-gamma (INF-y) gibi proinflamatuar sitokinlerin üretimini azaltarak ve T helper 2 (Th2) hücrelerinden anti-inflamatuar sitokin salınımını sağ- layarak edinsel bağışık yanıtın düzenlenmesinde de rol almaktadır (8). Böylece COVID-19 hastalarında gelişen sitokin fırtınasını ve çoklu organ yetmezliğini önleyebileceği düşünülmektedir (6).

D vitamini eksikliği, bütün yaş gruplarında önemli bir küresel halk sağlığı sorunudur (9). Dünya çapında bir milyardan fazla insanın $D$ vitamini eksikliği olduğu tahmin edilmektedir. Yaşılıarda, obez hastalarda, huzurevi sakinlerinde ve hastanede yatan hastalarda $D$ vitamini eksikliğinin daha fazla olduğu tespit edilmiştir (10). Vitamin D eksikliği, kardiyovasküler hastalık, tip 2 diabetes mellitus, metabolik sendrom, depresyon, kanser ve ölüm oranlarında artış ile ilişkilendirilmektedir. Hafif düzeyde vitamin D eksikliği genellikle semptom oluş̧urmasa da, halsizlik ve yaygın vücut ağrısı gibi şikayetler gözlenebilmektedir (11).

Dünyanın çeşitli yerlerinde gerçekleştirilen çalışmalar COVID-19 tanısı almış hastalarda vitamin D seviyelerinin COVID-19 tanıSı olmayan hastalara göre daha düşük olduğunu göstermektedir (12-14) Liu ve arkadaşları tarafından yayınlanmış sistematik derlemede, COVID-19 tanılı hastalarda vitamin $D$ seviyelerinin diğer hastalara göre daha düşük olduğu ve düşük $D$ vitamini düzeylerinin COVID-19 riskinde artış ile ilişkili olabileceği belirtilmiştir (13). Aynı konudaki diğer bir sistematik derlemede ise vitamin $\mathrm{D}$ eksikliğinin $\mathrm{CO}$ VID-19 hastalık riskini artırmadığı tespit edilmiştir (15).

Tanımlayıcı ve gözlemsel çalışmalarda D vitamini eksikliği olan hastalarda mortalite ve ciddi seyirli vaka sayısının daha yaygın olduğu belirtilmektedir (15-17). Yisak ve arkadaşları tarafından Vitamin D eksikliğinin hastalık şiddetinde artış ile ilişkili olduğu saptanmıştır (11). Yirmi yedi çalışmanın değerlendirildiği bir meta-analizde COVID-19 hastalarındaki vitamin D eksikliğiyle hastalık şiddeti, hastaneye yatış ve mortalite oranları arasında anlamlı ilişki saptandığı rapor edilmiştir (15). Yine yakın dönemde yayımlanan bir çalışmada ileri yaştaki COVID-19 hastalarında D vitamini eksikliği ile hastalık süresinde uzama, akciğer tutulumunda ve ölüm riskinde artış arasında istatistiksel olarak anlamlı ilişkili saptandığı belirtilmiştir (18).

D vitamininin COVID-19'a karşı potansiyel faydasına ilişkin umut verici kanıtlar göz önüne alındığında, farkI formlarda ve dozajlarda D vitamini takviyesinin etkisini araştırmak amacıyla çalışmalar yürütülmektedir. Yirmi beş randomize kontrollü çalışmanın değerlendirildiği bir meta-analizde vitamin $\mathrm{D}$ takviyesinin akut solunum yolu enfeksiyonu riskini azaltabileceği belirtilmektedir (19). Ling ve arkadaşlarının çok merkezli gözlemsel çalışmalarında bazal vitamin D düzeylerinden bağımsız olarak yüksek doz kolekalsiferol teda- 
visinin COVID-19 hastalarındaki mortaliteyi azalttığı tespit edilmiştir (20). Benzer şekilde çift kör randomize kontrollü bir pilot çalışmada COVID-19 nedeniyle hastanede yatışı gereken hastalara vitamin D verilmesiyle hastalığın şiddetinin ve yoğun bakım gereksiniminin azaldığı gösterilmiştir (3). Brezilya'da, tek ve yüksek doz D vitamini uygulamasının değerlendirildiği çok merkezli çift kör randomize kontrollü bir çalışmada ise $D$ vitamini verilmesinin hastanede yatış süresi, yoğun bakım intiyacı ve mortalite üzerine etkisiz olduğu tespit edilmiş ve bulguların COVID-19 hastalarında yüksek doz D vitamini uygulamasını desteklemediği ifade edilmiştir (21).

Türk Endokrin ve Metabolizma Derneği kılavuzunda, D vitamini eksikliği için toplum taraması önerilmezken, yüksek riskli kişilerde 25(OH) D düzeyi ölçülmesi önerilmektedir. D vitamini düzeyinin $<20 \mathrm{ng} / \mathrm{mL}$ olmasının tedavi gerektirdiği, yetişkinlerde günlük optimal D vitamini ihtiyacının 800-1500 IU/gün olduğu belirtilmektedir (22). Vitamin D'nin çok yüksek dozlarda uygunsuz kullanımı hiperkalsemi, renal yetmezlik vb. bulgularla karşımıza çıkan intoksikasyona neden olabilmektedir (23).

\section{Vitamin C}

C vitamini (askorbik asit), suda eriyebilen, insan vücudunda depolanmayan ve fazlası vücuttan ter ya da idrar yoluyla atılan esansiyel bir vitamin türüdür (12). C vitamini metabolizmada sentezlenemediği için günlük diyetle yeterli miktarda C vitamini alınmalıdır. En iyi kaynakları turunçgiller, yeşil biber, çilek, brokoli, yeşil yapraklılar ve patatestir (24-26). C vitamininin bağışıklık hücrelerinin etkinliğini arttırarak, anti-enflamatuar ve antioksidan etkisiyle bağışıklık sistemini modüle ettiği bilinmektedir. Nötrofillerin kemotaksisini ve fagositoz yeteneğini, makrofajların aktivasyonunu, interferon üretimini, T-lenfositlerin olgunlaşmasını arttırır ve virüslerin çoğalmasını engeller (27). Enfeksiyonlar sırasında üretilen reaktif oksijen türlerinin zararlı etkilerini nötralize etmede de vitamin C'nin önemli bir rolü olduğu belirtilmektedir (27). Soğuk algınlığı ve pnömoni dahil olmak üzere çeşitli enfeksiyonlar sırasında plazma ve bağışıklık hücrelerinde vitamin C düzeylerinde düşüş olduğu ve enfekte kişilerde intiyacının arttığı bildirilmiştir (28). Enfeksiyonları önlemede ve/veya tedavi etmede kullanılması uzun süredir araştırmacıların ilgisini çekmektedir (29). Literatürde C vitamini yan etkisiyle ilgili az sayıda bildirim olup, epidemiyolojik veriler ishal, karında şişkinlik, erkeklerde böbrek oksalat taşı oluşumu ile ilişkili olabileceğini göstermektedir (30, 31). Ciddi sepsis hastalarında intravenöz askorbik asit uygulamasının güvenliğinin değerlendirildiği faz 1 çalışmasında, 50 ve 200 mg/kg/ gün dozlarının güvenli olduğu, iyi tolere edildiği, infla- masyon ve endotel hasarının biyobelirteçlerini olumlu yönde etkileyebileceği belirtilmiştir (32). Benzer şekilde yakın dönemde yayımlanan 17 COVID-19 hastasının değerlendirildiği çalışmada, intravenöz vitamin C uygulamasıyla yan etki gözlenmediği, inflamatuar belirteç düzeylerinde ise anlamlı azalma gözlendiği ifade edilmiştir (33). Shanghai'de yapılan bir çalıșmada da orta-şiddetli COVID-19 hastalarının tedavisinde yüksek doz IV vitamin C kullanımının inflamatuar yanıt, bağışıklık ve organ fonksiyonlarının iyileştirilmesi açısından faydalı olduğu rapor edilmiştir (34).

Çin'in Hubei eyaletinde üç merkezde gerçekleştirilen randomize kontrollü çalışmada 24 gr/gün intravenöz vitamin $C$ uygulamasının oksijenizasyona olumlu katkısı olduğu, IL-6 seviyelerinde azalma sağladığı fakat 28 günlük mortalite üzerine etkisiz olduğu saptanmış$\operatorname{tir}(35)$.

Çok merkezli, prospektif randomize klinik çalışmada COVID-19 hastalarının semptomlarının \%50 azalmasına kadar geçen süre, 8000 mg/gün askorbik asitin 2 veya 3 doza bölünerek uygulandığı 48 hastada 5.5 \pm 3.7 gün iken, standart tedavi alan 50 hastada $6.6 \pm$ 4.4 gün olarak bulunmuş, istatistiksel fark tespit edilmemiştir. Aynı çalışmada gruplar arasında hastaneye yatış ve mortalite açısından da fark saptanmamıştır (36). Kumari ve arkadaşlarının yapmış olduğu prospektif randomize kontrollü çalışmada $50 \mathrm{mg} / \mathrm{kg} / \mathrm{gün}$ IV vitamin C uygulamasıyla semptom ve hastane yatıș süresinde anlamlı azalma gözlenmiş, fakat mortalite oranları ve mekanik ventilasyon gereksiniminde fark saptanmamıştır (37).

\section{Sonuç}

Vitamin C ve D'nin hem doğal hem de edinsel bağışıklık sistemi üzerinde çok sayıda yararlı etkisi olduğu bilinmektedir. Vitamin C ve D takviyesinin COVID-19 hastalarında yararlı olabileceğini bildiren çalışmalar olduğu gibi etkisiz olduğunu bildiren yayınlar da bulunmaktadır. COVID-19'un tedavisinde her iki vitamin için de yüksek dozda kullanımı destekleyen yeterli kanıt bulunmamaktadır. Yüksek plazma düzeylerini sağlayacak kadar olmasa da en azından eksikliğini önleyecek kadar diyetle veya yerine koyma tedavisi ile alınmaları önerilir. Vitamin D ve vitamin C'nin COVID-19 açısından korunma ve tedavideki etkinliklerinin ve uygun dozlarının değerlendirildiği kanıt düzeyi yüksek çalışmalara intiyaç vardır.

\section{Kaynaklar}

1. Shakoor H, Feehan J, Al Dhaheri AS, Ali HI, Platat C, Ismail LC, et al. Immune-boosting role of vitamins D, C, E, zinc, selenium and omega-3 fatty acids: Could they help against COVID-19? 
Maturitas. 2021;143:1-9.

2. Wang $Y$, Wang $Y$, Chen $Y$, Qin $Q$. Unique epidemiological and clinical features of the emerging 2019 novel coronavirus pneumonia (COVID-19) implicate special control measures. J Med Virol. 2020;92(6):568-76.

3. Entrenas Castillo M, Entrenas Costa LM, Vaquero Barrios JM, Alcala Diaz JF, Lopez Miranda J, Bouillon R, et al. "Effect of calcifediol treatment and best available therapy versus best available therapy on intensive care unit admission and mortality among patients hospitalized for COVID-19: A pilot randomized clinical study". J Steroid Biochem Mol Biol. 2020;203:105751.

4. Deluca HF. History of the discovery of vitamin D and its active metabolites. Bonekey Rep. 2014;3:479.

5. Edwards M, Cole Z, Harvey N, Cooper CJJARCP. The global epidemiology of vitamin D status. 2014;3(3):148-58.

6. Charoenngam N, Shirvani A, Holick MF. Vitamin D and Its Potential Benefit for the COVID-19 Pandemic. Endocr Pract. 2021.

7. Hansdottir S, Monick MM, Hinde SL, Lovan N, Look DC, Hunninghake GW. Respiratory epithelial cells convert inactive vitamin $D$ to its active form: potential effects on host defense. J Immunol. 2008;181(10):7090-9.

8. Jeffery LE, Burke F, Mura M, Zheng $Y$, Qureshi OS, Hewison $\mathrm{M}$, et al. 1,25-Dihydroxyvitamin D3 and IL-2 combine to inhibit $\mathrm{T}$ cell production of inflammatory cytokines and promote development of regulatory T cells expressing CTLA-4 and FoxP3. J Immunol. 2009;183(9):5458-67.

9. Palacios $\mathrm{C}$, Gonzalez L. Is vitamin D deficiency a major global public health problem? J Steroid Biochem Mol Biol. 2014;144 Pt A:138-45.

10. Sizar O, Khare S, Goyal A, Bansal P, Givler A. Vitamin D Deficiency. StatPearls. Treasure Island (FL)2021.

11. Yisak H, Ewunetei A, Kefale B, Mamuye M, Teshome F, Ambaw B, et al. Effects of Vitamin D on COVID-19 Infection and Prognosis: A Systematic Review. Risk Manag Healthc Policy. 2021:14:31-8

12. D'Avolio A, Avataneo V, Manca A, Cusato J, De Nicolo A, Lucchini R, et al. 25-Hydroxyvitamin D Concentrations Are Lower in Patients with Positive PCR for SARS-CoV-2. Nutrients. 2020;12(5)

13. Liu N, Sun J, Wang X, Zhang T, Zhao M, Li H. Low vitamin D status is associated with coronavirus disease 2019 outcomes: a systematic review and meta-analysis. Int J Infect Dis. 2021;104:58-64.

14. Im JH, Je YS, Baek J, Chung MH, Kwon HY, Lee JS. Nutritional status of patients with COVID-19. Int J Infect Dis. 2020:100:390-3.

15. Pereira M, Dantas Damascena A, Galvao Azevedo LM, de Almeida Oliveira T, da Mota Santana J. Vitamin D deficiency agg ravates COVID-19: systematic review and meta-analysis. Crit Rev Food Sci Nutr. 2020:1-9.

16. Lau FH, Majumder R, Torabi R, Saeg F, Hoffman R, Cirillo JD, et al. Vitamin D insufficiency is prevalent in severe COVID-19. 2020:2020.04.24.20075838.

17. Panagiotou G, Tee SA, Ihsan Y, Athar W, Marchitelli G, Kelly $\mathrm{D}$, et al. Low serum 25-hydroxyvitamin D (25[OH]D) levels in patients hospitalized with COVID-19 are associated with greater disease severity. Clin Endocrinol (Oxf). 2020;93(4):508-11.

18. Sulli A, Gotelli E, Casabella A, Paolino S, Pizzorni C, Alessandri E, et al. Vitamin D and Lung Outcomes in Elderly COVID-19 Patients. Nutrients. 2021;13(3).

19. Martineau AR, Jolliffe DA, Hooper RL, Greenberg L, Aloia JF, Bergman $\mathrm{P}$, et al. Vitamin $\mathrm{D}$ supplementation to prevent acute respiratory tract infections: systematic review and meta-analysis of individual participant data. BMJ. 2017;356:i6583.

20. Ling SF, Broad E, Murphy R, Pappachan JM, Pardesi-Newton S, Kong MF, et al. High-Dose Cholecalciferol Booster Therapy is Associated with a Reduced Risk of Mortality in Patients with COVID-19: A Cross-Sectional Multi-Centre Observational
Study. Nutrients. 2020;12(12)

21. Murai IH, Fernandes AL, Sales LP, Pinto AJ, Goessler $\mathrm{KF}$, Duran CSC, et al. Effect of a Single High Dose of Vitamin D3 on Hospital Length of Stay in Patients With Moderate to Severe COVID-19: A Randomized Clinical Trial. JAMA. 2021;325(11):1053-60.

22. Türkiye Endokrinoloji ve Metabolizma Derneği. Osteoporoz ve metabolik kemik hastalıkları tanı ve tedavi kılavuzu. 15.ed. Ankara;2020. Available from: https://temd.org.tr/admin/uploads/ tbl_kilavuz/20210104143325-2021tbl_kilavuz5e76bb3d16.pdf.

23. Rudneva LF, Androsova LA. [Long-term outcomes after acute vitamin D3 intoxication]. Vopr Pitan. 2004;73(4):11-3.

24. Kashiouris MG, L'Heureux M, Cable CA, Fisher BJ, Leichtle $\mathrm{SW}$, Fowler AA. The Emerging Role of Vitamin C as a Treatment for Sepsis. Nutrients. 2020;12(2).

25. Maxfield L, Crane JS. Vitamin C Deficiency. StatPearls. Treasure Island (FL)2021.

26. Bakan S, Deveboynu SN, Kartal FT. COVID-19 Pandemisinde Bağışıkık Üzerine Antioksidan Vitaminlerin Etkisi.3:140-8.

27. Hemila H. Vitamin C and Infections. Nutrients. 2017;9(4).

28. Carr AC, Maggini S. Vitamin C and Immune Function. Nutrients. 2017;9(11).

29. Farjana M, Moni A, Sohag AAM, Hasan A, Hannan MA, Hossain MG, et al. Repositioning Vitamin C as a Promising Option to Alleviate Complications associated with COVID-19. Infect Chemother. 2020;52(4):461-77.

30. Ferraro PM, Curhan GC, Gambaro G, Taylor EN. Total, Dietary, and Supplemental Vitamin C Intake and Risk of Incident Kidney Stones. Am J Kidney Dis. 2016;67(3):400-7.

31. Thomas LD, Elinder CG, Tiselius HG, Wolk A, Akesson A. Ascorbic acid supplements and kidney stone incidence among men: a prospective study. JAMA Intern Med. 2013;173(5):3868.

32. Fowler AA, 3rd, Syed AA, Knowlson S, Sculthorpe R, Farthing D, DeWilde C, et al. Phase I safety trial of intravenous ascorbic acid in patients with severe sepsis. J Transl Med. 2014;12:32.

33. Hiedra R, Lo KB, Elbashabsheh M, Gul F, Wright RM, Albano $\mathrm{J}$, et al. The use of IV vitamin C for patients with COVID-19: a case series. Expert Rev Anti Infect Ther. 2020;18(12):1259-61.

34. Zhao B, Ling Y, Li J, Peng Y, Huang J, Wang Y, et al. Beneficial aspects of high dose intravenous vitamin $C$ on patients with COVID-19 pneumonia in severe condition: a retrospective case series study. Ann Palliat Med. 2021;10(2):1599-609.

35. Zhang J, Rao X, Li Y, Zhu Y, Liu F, Guo G, et al. Pilot trial of high-dose vitamin $C$ in critically ill COVID-19 patients. Ann Intensive Care. 2021;11(1):5.

36. Thomas S, Patel D, Bittel B, Wolski K, Wang Q, Kumar A, et al. Effect of High-Dose Zinc and Ascorbic Acid Supplementation vs Usual Care on Symptom Length and Reduction Among Ambulatory Patients With SARS-CoV-2 Infection: The COVID A to Z Randomized Clinical Trial. JAMA Netw Open. 2021;4(2):e210369.

37. Kumari P, Dembra S, Dembra P, Bhawna F, Gul A, Ali B, et al. The Role of Vitamin C as Adjuvant Therapy in COVID-19. Cureus. 2020;12(11):e11779. 